\title{
Motivation, Effort, and Distraction Factors Associated with Student Performance in an Undergraduate Financial Management Course: An Empirical Study at a US Public Residential University
}

\author{
Keshav Gupta \\ Kutztown University \\ Mostafa Maksy \\ Kutztown University
}

This is perhaps the first study of the impact of nineteen variables, divided into five factors, on students' performance in an Undergraduate Financial Management course. We find that grades students would like to make in the course and their plan to take Chartered Financial Analyst or Certified Financial Planner exam among the motivation variables, their homework grades and attendance among the effort variables, their self-perceived math ability, and their cumulative grade point average have strong and consistent relationship with their performance in the course. Among the distraction factors, only job hours show some weak negative relationship with students' overall performance.

Keywords: motivation, effort, distraction, prior ability, student performance, financial management

\section{INTRODUCTION}

Prior research studies have explored several variables (e.g., general academic performance, aptitude, prior exposure to mathematics, prior exposure to accounting, age, gender, motivation, effort, and some intervening variables) that may be associated with students' performance in college-level courses. It is widely believed that motivation and effort significantly influence students' performance in college. However, the review of prior research indicates that very few studies have investigated their impact on a required Undergraduate Financial Management (UFM) course in an integrated way. This study investigates the associations between selected motivation, effort, distraction, self-perceived ability, and prior ability factors and student performance in an UFM course, in a comprehensive manner.

As proxies for motivation, we use the grade the students would like to make in the course, their intention to take the Certified Public Accountant (CPA) examination, their intention to take the Chartered Financial Analyst (CFA) or Certified Financial Planner (CFP) exam, and their intention to attend graduate school. As proxies for effort, we use the number of weekly study hours for the course, the number of total weekly study hours for all courses, homework grade, and class attendance. As proxies for distraction, we use the number of work hours per week, the type of job (whether it is related to accounting, finance, business in general, or other), the number of courses taken per semester, and the number of credit hours taken per semester. Students were also asked to report their self-perceived abilities in math, writing, 
reading, and listening. Students' prior ability is measured by the grade earned in Financial and Managerial Accounting courses, and cumulative grade point average, as reported by the students. Students' performance in the course is measured in three different ways: the letter grade in the course, overall percent score in the course, and the percent score for in class tests.

One of the objectives of this study is to identify the motivation and effort factors that help students to perform well and also the factors that distract them from performing well. Instructors may then emphasize the motivation and effort factors and discourage the distraction factors. Also, the study could help us determine whether students' self-assessed writing, math, reading, and listening abilities have impact on their performance in an UFM course.

The review of literature shows that this is the first detailed study of the impact of 19 variables, divided into five factors, on students' performance in an UFM course. After the review of prior research, we present discussion of the hypotheses, the research methodology, the study results, and conclusions and recommendations. Finally, we present the study's limitations and suggestions for further research.

\section{REVIEW OF PRIOR RESEARCH}

In the finance area, Paulsen and Gentry (1995), Chan, Shum, and Wright (1997), Sen, Joyce, Farrel, and Toutant (1997), Didia and Hasnat (1998), Van Ness, Van Ness, and Adkins (2000), Johnson, Joyce, and Sen (2002), Biktimirov and Klassen (2008), and Maksy and Rezvanian (2017) found cumulative grade point average to be a strong predictor of grade in the UFM course that is required of all business majors.

Finance and accounting are subject areas that require quantitative skills and accumulation of prior knowledge. Thus, several studies have investigated the impact of prior exposure to mathematics and accounting on performance in college finance and accounting courses. With regard to the UFM courses, the evidence is mixed. Chan et al. (1997) showed that self-reported quantitative skills have insignificant impact on students' course score, Sen et al. (1997) reported positive relationship between completion of pre-requisites and performance in the course. Grover, Heck, and Heck (2010) reported significant explanatory power for pre-test scores in math, accounting, and economics. Didia and Hasnat (1998) found mixed results with math grade being significant predictor of course grade for ordinary-least-square regression model (OLS) but not for the ordered-probit model. Similarly, Maksy and Rezvanian (2017) found positive association between students self-perceived math ability and course grade under bivariate but not multivariate tests. Both Didia and Hasnat (1998) and Maksy and Rezvanian (2017) found strong evidence, using both bivariate and multivariate tests, that grades in accounting pre-requisite courses have predictive value for grades in the UFM course.

Prior studies about the influence of motivation and effort on student performance report mostly similar but also some conflicting results. For example, Pascarella and Terenzini (1991) reported that motivation and effort, among other factors, significantly influence students' performance in college. Wooten (1998) found that motivation significantly affects effort which in turn significantly affects performance in an introductory accounting course. Maksy and Zheng (2008) used "the grade the student would like to earn" as a proxy for motivation and found it to be significantly associated with the student's performance in advanced accounting and auditing courses. Paulsen and Gentry (1995), using a survey instrument reported that students' academic performance in a large UFM course significantly related to several motivational variables such as intrinsic and extrinsic goal orientations and task value, and learning strategy variables, including time, study, and effort. Maksy and Rezvanian (2017) found mixed results for motivation variables that they used. Nofsinger and Petry (1999) fond that students taking close to full (but not more) time to finish the test, studying eight to nine hours before the test, and studying with only one other person improved their performance in an UFM course. Johnson et al. (2002) utilized computerized quizzes and analyzed the effect of objectively measured effort on students' performance in an UFM course. They showed that effort remained significant in explaining the course performance, after controlling for aptitude, ability, and gender. Rich (2006) used students' homework preparedness and unpreparedness in class as a proxy of effort and non-effort. He found significant positive relationship 
with exam grade in percent for the former and negative relationship for the latter. Biktimirov and Klassen (2008) found weak association between hits to course management system and grade in an UFM course. In contrast, using students' self-reported data, Didia and Hasnat (1998) presented very week counterintuitive evidence that more time spent studying per week lowered the grade in the UFM course. This was supported by one of the two OLS models but not by the ordered-probit models.

In recent years, there has been increased interest in studying the influence of intervening variables on students' performance. Paulsen and Gentry (1995) found that academic performance in a large UFM class is significantly related to control over learning, test anxiety, self-efficacy, elaboration, organization and metacognition. Wooten (1998) found no statistically significant relationship between work, family, and extra-curricular conflicts and students' performance in an introduction to accounting course. Chan et al. (1997) found no statistically significant relationship between performance in an UFM course and attendance, credit hours enrolled, and number of weekly work hours. In a similar vein, Van Ness et al. (2000) found no statistically significant relationship between students' full time or part time status and grades in an UFM class. Maksy and Rezvanian (2017) reported no significant negative effect of job hours, job type, or course load, on students' performance in an UFM course. Didia and Hasnat (1998) found strong positive relationship between number of credit hours enrolled in the semester and course grades. This result seems to be counter intuitive; they attribute it to brighter students taking more credit hours. However, they did not provide any evidence to support their conjecture. Rich (2006) reported significant negative relationship between class absences and being late to the class, and exam percent score.

Age and gender are two demographic variables that receive less attention than the factors discussed above, and the results are inconclusive. Chan et al. (1997) and Van Ness et al. (2000) found no statistically significant relationship between grade in an UFM and gender or age of students. Didia and Hasnat (1998), Henebry and Diamond (1998) and Johnson et al. (2002) also did not find any statistically significant relationship between an UFM course score and gender of students. However, Henebry and Diamond (1998) showed that both male and female students earn significantly higher grades in courses taught by female instructors. This difference was not attributable to adjunct, tenure track, or tenured status of instructors. Sen et al. (1997), on the other hand, showed that female student performed significantly worse than male students in UFM courses at two different mid-western universities. Didia and Hasnat (1998) showed that age has statistically significant positive coefficient for OLS but not for ordered-probit model.

While prior research shows some conflicting results, it is not our purpose in this study to resolve all these conflicts. Our hope is to provide additional insight into the areas with some general agreement. We do this by taking a comprehensive look at 19 variables divided into five factors. We also look at some new measures of motivation like students' intention to take certification exam or to go to a graduate school. Moreover, we investigate the impact of three specific measures of prior abilities on student performance, and then use them as control variables while testing for the association between motivation, effort, distraction, and self-perceived abilities factors, and student performance in the UFM course. This reduces the possibility that any reported relationship between those factors and students' performance may be due to relationship between prior ability and performance.

\section{STUDY HYPOTHESES}

Hypotheses are grouped under broad categories of factors. To prevent redundancy, all hypotheses are presented in the alternate form only.

\section{Motivation Variables}

Hypotheses 1 to 4 are that students who would like to make higher grades in the UFM course, intend to take CPA exam, intend to take CFA or CFP exam, or intend to attend Graduate School are motivated to perform well. This implies positive relationships between those motivation variables and students' performance in the course. 


\section{Effort Variables}

Next four hypotheses state that there are significant positive relationships between the four effort variables, homework grade, attendance, course study hours, and total study hours, and students' performance. Also, motivated students are expected to perform well in assigned homework, maintain good attendance, and spend more hours per week to study for the course and for other courses as well in order to earn a higher grade in the UFM course. We use correlations table to test for relationships between motivation and effort factors.

\section{Distraction Variables}

Hypotheses 9 to 12 are related to the four distraction variables. We expect negative relationship between students' performance in the course and job hours, course load, and credit load. Job type coding gives higher number to accounting and finance related jobs which may be less of a distraction to students and may even enhance students' learning. Therefore, in tests where job type codes are used as independent variables, we expect positive relationship between job type and students' performance in the course.

It is possible that distraction factors may offset each other thereby cancelling out any single factor's effect. For example, a student who works higher number of hours per week may take fewer courses or fewer credit hours, and vice versa, so that there is no negative effect on performance. To account for that, we test the effect of each distraction factor on students' performance while controlling for the other three factors. We also test the relationship of students' performance with job hours and credit hours combined. Finally, we investigate the association between the distraction factors and the four effort factors.

\section{Self-Perceived Ability}

Hypothesis numbers 13 to 16 test for relationship between students' performance in the UFM course and their self-perceived writing, math, reading, and listening abilities. We propose that students who accurately perceive their abilities to be higher in these areas perform better in the UFM course. If students make reasonably accurate assessment of their abilities and if these abilities relate to the performance in the course, there should be significant positive relationship between these abilities and students' performance in the course. A lack of relationship between certain abilities and performance could be due to the possibility that those abilities are not relevant to the performance in the course and/or due to students' inaccurate assessment of their abilities.

\section{Prior Ability}

Financial Accounting and Managerial Accounting are pre-requisite for the UFM course at most colleges. Next three hypotheses posit positive relationship between students' performance in the UFM course and their grades in Financial Accounting, Managerial Accounting, and also their cumulative grade point average.

We do not propose any prior hypotheses for the gender, age, and primary major of the students. We included these variables in the study for the purpose of comparing our results, with prior research. Prior research shows mixed results for these variables.

\section{RESEARCH METHODOLOGY}

Before doing the survey, authors had to take the National Institute of Health (NIH)'s training course titled "Protecting Human Research Participants," and pass the test given at the end of the course. The authors then submitted a 10-page application, together with a copy of the survey instrument and the certificate of NIH course completion, to the University's Institutional Review Board (IRB) for approval. Our survey questions were based on Ingram, Albright, and Baldwin (2002) and included, some demographic and other information. IRB made only one modification to the survey instrument by adding the statement that, "Participation in the survey is completely voluntary." The university enrolls about 
9,000 students, and the College of Business enrolls about 1,600 students. It is a state-owned university that has public access as a major part of its mission statement.

\section{Study Variables}

The list of variables, first three of which are students' course performance measures, along with full explanation is presented below with abbreviations in parentheses. Where applicable, the possible responses on the survey instrument are listed in brackets "[ ]."

1. Letter Grade $(L G)$ : The letter grade: A, B, C, D, and F students earned for the course are converted to $4,3,2,1$, and 0 points respectively.

2. Overall Points in Percent (OPP): The total number of percentage points calculated by giving $78 \%$ weight to three tests, $15 \%$ weight to homework grade and $7 \%$ weight to the grade in spreadsheet assignment related to time value of money.

3. In-Class Test Score in Percent (ICTP): Percentage points the student earned in three tests given in class. The tests are non-cumulative with $40 \%$ weight to two problems and $60 \%$ weight to 30 multiple choice questions and up to $10 \%$ extra credit for multiple choice questions based on The Wall Street Journal quizzes with maximum grade capped at $100 \%$. Since homework grade is used in calculating LG and OPP, any relationship between homework grade and those variables could be part statistical and part deterministic. ICTP as a performance variable does not have that problem and is a cleaner measure of any statistical relationship between homework grade and students' performance.

4. Grade Make (GMK): "The grade I would like to make in the course is" [a. an A = 4; b. at least a $\mathrm{B}=3 \mathrm{c}$. at least a $\mathrm{C}=2$; $\mathrm{d}$. a $\mathrm{D}$ is fine with $\mathrm{me}=1$ ].

5. $C P A(C P A)$ : "Are you planning to take the CPA exam?" [Yes $=2 ;$ No $=0$; Maybe $=1]$. For the Difference in Means Test, we combine "Yes" and "Maybe" into one category because there were only 12 "Yes" and 19 "Maybe" versus 61 "No."

6. $C F A / C F P(C F N)$ : "Are you planning to take the Chartered Financial Analyst (CFA) or Certified Financial Planner (CFP) exam?" [Yes $=2$; No $=0$; Maybe $=1]$. For the Difference in Means Test we combine "Yes" and "Maybe" into one category because there were only 2 "Yes" and 14 "Maybe" versus 76 "No."

7. Graduate School (GSC): "Are you planning to attend graduate school?" [Yes, at this school= 2 ; Yes, but at another school $=3$; No $=0$; Maybe $=1]$. For the Difference in Means Test we combine "Yes at this school," frequency 3, with "Yes, but at another school," frequency 24, and "Maybe," frequency 45, for a total of 72 versus 20 "No."

8. Home Work Grade in Percent (HWG): Percentage points earned by students in online homework assignments from the textbook on CengageNOW and online quizzes on Desire2Learn (D2L) related to current business, economic, and financial news in The Wall Street Journal.

9. Attendance (ATP): Percentage of classes attended by a student. The instructor took the attendance in every class.

10. Course Study Hours (CSH): "In an average week, how many hours do you study for this course?" [ hours].

11. Total Study Hours (TSH): "In an average week, how many hours do you study overall?" [__ hours]. We find that TSH is highly correlated with CSH (0.745 correlation coefficient under Pearson partial correlation, Table 10, with $1 \%$ or better level of statistical significance). Thus, we do not use $\mathrm{CSH}$ in the regression analysis to avoid the multicolinearity problem. We drop CSH because some students reported very high CSH relative to their TSH.

12. Job Hours $(J B H)$ : "In an average week, how many hours do you work at a job?" hours].

13. Job Type (JBT): "My job is" [Accounting related $=4$; Finance related $=3$; Business related (but not accounting or finance) $=2$; Other $=1]$. For the Difference in Means Test we 
combined "Finance related," frequency 1, "Accounting related," frequency 1, and "Business related," frequency 30 , for a total of 32 versus 55 "Other."

14. Course Load (COL): "How many courses are you taking this semester?" [__ courses].

15. Credit Load (CRL): "How many credit hours are you taking this semester?" [ credit hours]. We find that COL is highly correlated with CRL (0.919 correlation coefficient under Pearson partial correlation, Table 10 , with $1 \%$ or better level of statistical significance). Thus, we do not use COL in the regression analysis to avoid the multicolinearity problem. We drop COL because it may include some courses worth less than three credit hours load.

16. Writing Ability (WRA): "My writing ability is" [a. Very good $=4$; b. Good $=3$; c. Average $=$ 2 ; d. Poor $=1]$.

17. Math Ability (MTA): "My math ability is" [a. Poor = 1; b. Average = 2; c. Good =3; d. Very Good $=4]$. We scrambled the order of Very Good to Poor on the survey instrument to diminish the possibility of students marking off the same letter in all four variables. Moreover, we put math in the middle to reduce the possibility of students marking writing, reading, and listening abilities the same.

18. Reading Ability (RDA): "My reading ability is" [a. Poor $=1 ; \mathrm{b}$. Average = 2; . Good = 3; d. Very Good $=4]$.

19. Listening Ability (LNA): "My listening ability is" [a. Very good =4; b. Good = 3; c. Average $=2$; d. Poor $=1]$.

20. Financial Accounting Grade (FNAG): "What was your grade for ACC 121 (Financial Accounting)?" [ $\mathrm{A} ; \quad \ldots \mathrm{B} ; \ldots \mathrm{C} ; \ldots \mathrm{D}]$. For both Financial Accounting and Managerial Accounting, we used grade points of $4,3,2$, and 1 for A, B, C, and D respectively. F was not a possible grade in either course because passing both the courses is a pre-requisite for taking the UFM course.

21. Managerial Accounting Grade (MGAG): "What was your grade for ACC 122 (Managerial Accounting)?" [ A; B B _ C

22. Cumulative Grade Point Average (GPA): "What is your GPA Overall?" [_] ].

23. Gender $(G E N)$ : "Your gender" [Male $=1 ;$ Female $=2]$

24. Age (AGE): "Your age group" $[18-22=1 ; 23-27=2 ; 27+=3]$. Since 70 out of 91 reporting students were in the 18-22 age group, we combined the remaining two groups for the Difference in Means Test.

25. Primary Major (PMAJ): "My primary major is" $[$ Accounting $=5$; Finance $=4$; Marketing = 3; Management $=2$; Other $=1$.] We combined Accounting and Finance majors into first category for the total of 25 and the rest in second category for the Difference in Means Test.

\section{Study Sample}

Using the IRB approved survey instrument, we surveyed students at the beginning of Fall 2010 and Spring 2011 semesters. The students were enrolled in four sections of the UFM course taught by the same instructor eliminating any instructor effect. Only 100 of the 110 students enrolled in those section filled out the questionnaire. The final sample included 92 useful responses as some students dropped the course or did not finish the course after filling out the questionnaire. Other students did not provide their student IDs so we could not determine the value of performance measures for them. The instructor teaching the course provided the data (using only students' ID numbers) representing the three performance measures (LG, OPP, and ICTP) and two effort variables (HWG and ATP).

Two different graduate students entered the same data from the questionnaires on two separate Excel spreadsheets. The authors matched the two spread sheets and resolved any discrepancies by referring to the original questionnaires. This virtually eliminated any data entry errors.

\section{Data Analysis}

To test the formulated hypotheses, we use the Difference in Means Test (DMT) for variables which can be easily divided into two groups. Some of these variables may also exhibit non-linear relationship 
with performance. E.g. credit load up to 15 hours may not hurt the performance versus someone taking 9 hours of credit load, but 18 or 21 hours of credit can negatively affect performance. We also perform One-Way Analysis of Variance (ANOVA) and calculate Pearson Correlation Coefficients (CORR) for all

the variables. Finally, we run Ordinary-Least-Square Regression (OLS) with all but two variables (CSH and COL) due to multicollinearity issue with TSH and CRL respectively.

\section{STUDY RESULTS}

Table 1 presents descriptive statistics $(\mathrm{N}$ : the number of data points, the mean, the standard deviation, the minimum, and the maximum), for each of the 22 non-binary variables of the study. The table shows the average LG in the course of only 2.16 versus 2.78 in the Financial Accounting course, 2.74 in the Managerial Accounting course, and 2.90 GPA. Didia and Hasnat (1998) reported the UFM course average grade of only 1.85, average grade of 2.71 in accounting pre-requisite courses, and GPA of 2.61. Maksy and Rezvanian (2017) reported high mean LG in the course of 2.82 versus 2.96 in Financial Accounting course, 2.90 in Managerial Accounting course, and 3.21 GPA. Our study shows difference between the average grade in the UFM course and pre-requisite accounting courses to be -0.62 and -0.58 respectively. It is somewhat smaller but similar to -0.86 reported by Didia and Hasnet (1998). Maksy and Rezvanian (2017) showed much smaller differences in absolute terms. Similarly, the difference between average grade and GPA of -0.74 for our study is almost identical to -0.76 for Didia and Hasnet (1998) but for Maksy and Rezvanian (2017) it was only -0.39. The average GMK of 3.38 appears to be unrealistic in view of 1.22 lower average LG in the course, however that was not the case with Maksy and Rezvanian (2017) where the difference was only -0.31 .

Students' self-reported average study time for the course (CSH) is 3.51 hours per week which is only $59 \%$ of the 6 hours per week recommended by the instructor both verbally and in the syllabus. In comparison, Didia and Hasnet (1998) reported 3.92 hours per week of study time for the UFM course. Students' self-reported average total study time for all courses (TSH) is only 11.17 hours per week compared to the suggested 29.82 hours per week based on average of 14.91 semester credit hours course load and the recommended two hours per semester credit hour study time. This is even lower than the average Business Majors study time of 13.14 hours for 2004 reported by Babcock and Marks (2011). 
TABLE 1

DESCRIPTIVE STATISTICS FOR NON-BINARY VARIABLES IN THE STUDY

\begin{tabular}{|l|c|c|c|c|c|}
\hline & $\mathrm{N}$ & Mean & $\begin{array}{c}\text { Standard } \\
\text { Deviation }\end{array}$ & Minimum & Maximum \\
\hline Letter Grade (LG) & & & 1.14 & 0.00 & 4.00 \\
\hline Overall Points in Percent (OPP) & 92 & 75.60 & 11.82 & 36.00 & 98.00 \\
\hline In-Class Tests in Percent (ICTP) & 92 & 74.76 & 11.27 & 41.00 & 98.00 \\
\hline Grade Make (GMK) & 91 & 3.38 & 0.61 & 2.00 & 4.00 \\
\hline CPA & 92 & 0.47 & 0.72 & 0 & 2 \\
\hline CFA/CFP (CFN) & 92 & 0.20 & 0.45 & 0 & 2 \\
\hline Graduate School (GSC) & 92 & 1.37 & 1.11 & 0 & 3 \\
\hline Home Work Grade in Percent (HWG) & 92 & 75.52 & 26.16 & 4.00 & 100.00 \\
\hline Attendance in Percent (ATP) & 92 & 83.16 & 15.40 & 43.00 & 100.00 \\
\hline Course Study Hours (CSH) & 91 & 3.51 & 2.46 & 1.00 & 15.00 \\
\hline Total Study Hours (TSH) & 90 & 11.17 & 7.30 & 2.00 & 45.00 \\
\hline Job Hours (JBH) & 90 & 18.76 & 13.24 & 0.00 & 50.00 \\
\hline Job Type (JBT) & 87 & 1.39 & 0.60 & 0 & 4 \\
\hline Course Load (COL) & 92 & 5.09 & 0.92 & 2 & 8 \\
\hline Credit Load (CRL) & 95 & 14.91 & 2.47 & 6 & 21 \\
\hline Writing Ability (WRA) & 91 & 3.10 & 0.63 & 2 & 4 \\
\hline Math Ability (MTA) & 91 & 2.86 & 0.84 & 1 & 4 \\
\hline Reading Ability (RDA) & 91 & 3.01 & 0.72 & 1 & 4 \\
\hline Listening Ability (LNA) & 91 & 3.19 & 0.68 & 1 & 4 \\
\hline Financial Accounting Grade (FNAG) & 91 & 2.78 & 0.83 & 1.00 & 4.00 \\
\hline $\begin{array}{l}\text { Managerial Accounting Grade } \\
\text { (MGAG) }\end{array}$ & 88 & 2.74 & 0.80 & 1.00 & 4.00 \\
\hline $\begin{array}{l}\text { Cumulative Grade Point Average } \\
\text { (GPA) }\end{array}$ & 83 & 2.90 & 0.52 & 1.94 & 4.00 \\
\hline
\end{tabular}

Average reported total study hours of 11.17 per week and job hours of 18.76 per week, in our survey, add to 29.93 hours. It is almost the same as the recommended study hours of 29.82 per week. Apparently, students' need to work is cutting into recommended study hours. Babcock and Marks (2011) show a decline in study hours by non-working students also. This could be due to instructors lowering the course rigor to meet the needs of the majority of working students. In that case non-working students may not find it necessary to study more to achieve their academic objective of a satisfactory grade. 
TABLE 2

DIFFERENCES IN MEANS OF PERFORMANCE MEASURES TEST FOR SELECTED INDEPENDENT VARIABLES

\begin{tabular}{|c|c|c|c|c|c|}
\hline Variable & Category & \begin{tabular}{|l}
$\begin{array}{l}\text { Number } \\
(\%)\end{array}$ \\
\end{tabular} & Mean LG & Mean OPP & Mean ICTP \\
\hline \multirow{3}{*}{$\mathrm{CFN}$} & Yes/Maybe & $16(17)$ & 2.81 & 82.81 & 81.81 \\
\hline & No & $76(83)$ & 2.03 & 74.08 & 73.28 \\
\hline & Difference/ p-value & & $0.78 / 0.011^{* *}$ & $8.73 / 0.007 * * *$ & $8.53 / 0.005 * * *$ \\
\hline \multirow{3}{*}{$\mathrm{CPA}$} & Yes/Maybe & $31(34)$ & 2.55 & 79.03 & 78.94 \\
\hline & No & $61(66)$ & 1.97 & 73.85 & 72.64 \\
\hline & Difference/ p-value & & $0.58 / 0.020 * *$ & $5.18 / 0.046 * *$ & $6.30 / 0.011 * *$ \\
\hline \multirow{3}{*}{ GSC } & Yes/Maybe & $72(78)$ & 2.26 & $76.81^{\prime}$ & 75.94 \\
\hline & No & $20(22)$ & 1.80 & 71.25 & 70.50 \\
\hline & Difference/ p-value & & $0.46 / 0.108$ & $5.56 / 0.063^{*}$ & $5.44 / 0.055^{*}$ \\
\hline \multirow{3}{*}{$\mathrm{CSH}$} & 6 hours or more & $11(12)$ & 2.36 & 78.18 & 73.45 \\
\hline & Less than 6 hours & $80(88)$ & 2.13 & 75.09 & 74.83 \\
\hline & Difference/ p-value & & $0.23 / 0.520$ & $3.09 / 0.418$ & $-1.38 / 0.708$ \\
\hline \multirow{3}{*}{ TSH } & 20 hours or more & $12(13)$ & 2.75 & 81.42 & 78.00 \\
\hline & Less than 20 hours & $78(87)$ & 2.06 & 74.60 & 74.29 \\
\hline & Difference/ p-value & & $0.69 / 0.054^{*}$ & $6.82 / 0.064 *$ & $3.71 / 0.292$ \\
\hline \multirow{3}{*}{ JBH } & 20 hours or more & $45(50)$ & 1.87 & 72.29 & 72.71 \\
\hline & Less than 20 hours & $45(50)$ & 2.42 & 78.42 & 76.42 \\
\hline & Difference/ p-value & & $-0.56 / 0.020 * *$ & $-6.13 / 0.012 * *$ & $-3.71 / 0.113$ \\
\hline \multirow{3}{*}{ JBT } & Other & $55(63)$ & 2.15 & 75.18 & 74.82 \\
\hline & Acc-Fin-Bus Rel. & $32(37)$ & 2.16 & 75.66 & 74.34 \\
\hline & Difference/ p-value & & $-0.01 / 0.967$ & $-0.48 / 0.860$ & $0.48 / 0.852$ \\
\hline \multirow{3}{*}{$\mathrm{COL}$} & 6 or more courses & $24(26)$ & 1.96 & 73.54 & 71.75 \\
\hline & Less than 6 courses & $68(74)$ & 2.24 & 76.32 & 75.82 \\
\hline & Difference/ p-value & & $-0.28 / 0.309$ & $-2.78 / 0.324$ & $-4.07 / 0.129$ \\
\hline \multirow{3}{*}{ CRL } & 18 or more credits & $18(20)$ & 1.83 & 72.56 & 70.39 \\
\hline & Less than 18 credits & $74(80)$ & 2.24 & 76.34 & 75.82 \\
\hline & Difference/ p-value & & $-0.41 / 0.173$ & $-3.78 / 0.225$ & $-5.43 / 0.066^{*}$ \\
\hline \multirow{3}{*}{ Gender } & Male & $55(60)$ & 2.15 & 75.29 & 75.16 \\
\hline & Female & $36(40)$ & 2.17 & 75.86 & 74.03 \\
\hline & Difference/ p-value & & $-0.02 / 0.932$ & $-0.57 / 0.824$ & $1.13 / 0.642$ \\
\hline \multirow{3}{*}{ Age } & Above 22 & $21(23)$ & 1.86 & 71.48 & 71.33 \\
\hline & $18-22$ & $70(77)$ & 2.24 & 76.73 & 75.73 \\
\hline & Difference/ p-value & & $-0.38 / 0.177$ & $-5.25 / 0.075^{*}$ & $-4.40 / 0.119$ \\
\hline \multirow{3}{*}{$\begin{array}{c}\text { Primary } \\
\text { Major }\end{array}$} & Accounting/Finance & $25(27)$ & 2.56 & 79.08 & 79.72 \\
\hline & Other & $67(73)$ & 2.01 & 74.30 & 72.91 \\
\hline & Difference/ p-value & & $0.55 / 0.041^{* *}$ & $4.78 / 0.084^{*}$ & $6.81 / 0.009 * * *$ \\
\hline
\end{tabular}

Table 2 presents Differences in Means Tests (DMT) for selected variables. It shows male to female ratio in the class of $60 \%$ to $40 \%$ and that the differences in their performance by all three measures are not statistically significant. The results are consistent with Chan et al. (1997), Didia and Hasnat (1998), Van Ness et al. (2000), Johnson et al. (2002), Rich (2006), and Grover et al. (2010). Two other studies found the role of gender in the finance course performance to be statistically significant. Sen et al. (1997) 
showed significant negative regression coefficient for females, while Henebry and Diamond (1998) showed significant positive difference in grade for the UFM courses taught by female professors.

With regard to age, Table 2 shows that $23 \%$ of the students were above the age of 22 years. They earned 5.25 lower mean OPP with p-value of $0.075^{* 1}$. The results for the other two performance measures are statistically insignificant. This is contrary to Didia and Hasnet (1998) who found positive and significant coefficient for the actual age variable in the OLS. Chan et al. (1997) and Van Ness et al. (2000) on the other hand found no significant relationship between age and grades assigned.

Table 2 also shows that only $27 \%$ of the students taking the UFM course are accounting or finance majors and they average 0.55 higher LG, 4.78 higher OPP, and 6.81 higher ICTP than other majors. The p-values are $0.041^{* *}, 0.084^{*}$, and $0.009^{* * *}$ respectively. This clearly shows that student choosing accounting or finance majors perform better in the financial management course. Perhaps they are choosing the correct major based on their aptitude and ability. They may also be more motivated to perform well in the UFM course. Results are consistent with Chan et al. (1997) and Sen et al. (1997). However, Sen et al. (1997) found significant positive coefficient for finance majors at only one of the two universities they studied. Van Ness et al. (2000) found no significant relationship between finance major and grade in the UFM course.

TABLE 3

ONE-WAY ANALYSIS OF VARIANCE BETWEEN PERFORMANCE MEASURES AND INDEPENDENT VARIABLES (ALL NUMBERS ARE FOR BETWEEN GROUPS ONLY)

\begin{tabular}{|c|c|c|c|c|c|c|c|}
\hline & \multicolumn{6}{|c|}{ Performance Variables } \\
\hline & & \multicolumn{2}{|c|}{ LGP } & \multicolumn{2}{|c|}{ OPP } & \multicolumn{2}{|c|}{ ICTP } \\
\hline Indep. Var. & DF & $\mathrm{F}$ & $\mathrm{p}$-value & $\mathrm{F}$ & p-value & $\mathrm{F}$ & p-value \\
\hline GMK & $2 / 88 / 90$ & 10.66 & $0.000 * * *$ & 8.69 & $0.000 * * *$ & 8.48 & $0.000 * * *$ \\
\hline $\mathrm{CPA}$ & $2 / 89 / 91$ & 2.88 & $0.061^{*}$ & 2.09 & 0.130 & 3.64 & $0.030 * *$ \\
\hline $\mathrm{CFN}$ & $2 / 89 / 91$ & 3.33 & $0.040 * *$ & 4.04 & $0.021 * *$ & 4.08 & $0.020 * *$ \\
\hline GSC & $3 / 88 / 91$ & 1.39 & 0.252 & 1.65 & 0.184 & 1.63 & 0.189 \\
\hline HWG & $47 / 44 / 91$ & 2.34 & $0.003 * * *$ & 3.03 & $0.000 * * *$ & 1.37 & 0.149 \\
\hline ATP & $17 / 74 / 91$ & 3.05 & $.000 * * *$ & 2.47 & $0.004 * * *$ & 1.93 & $0.028 * * *$ \\
\hline $\mathrm{CSH}$ & $15 / 75 / 90$ & 0.60 & 0.865 & 0.63 & 0.840 & 0.67 & 0.807 \\
\hline $\mathrm{TSH}$ & $21 / 68 / 89$ & 1.21 & 0.275 & 1.03 & 0.447 & 1.11 & 0.359 \\
\hline JBH & $24 / 65 / 89$ & 1.37 & 0.168 & 1.43 & 0.130 & 1.06 & 0.410 \\
\hline JBT & $4 / 82 / 86$ & 1.30 & 0.277 & 3.25 & $0.016 * *$ & 2.03 & $0.097 *$ \\
\hline $\mathrm{COL}$ & $5 / 86 / 91$ & 0.38 & 0.863 & 0.31 & 0.906 & 0.79 & 0.562 \\
\hline CRL & $10 / 81 / 91$ & 0.42 & 0.931 & 0.30 & 0.978 & 0.64 & 0.780 \\
\hline $\mathrm{JBH}+\mathrm{CRL}$ & $40 / 51 / 91$ & 1.29 & 0.191 & 1.262 & 0.215 & 1.296 & 0.190 \\
\hline WRA & $2 / 88 / 90$ & 0.26 & 0.772 & 0.28 & 0.757 & 0.42 & 0.657 \\
\hline MTA & $3 / 87 / 90$ & 6.37 & $0.001 * * *$ & 7.20 & $0.000 * * *$ & 9.88 & $0.000 * * *$ \\
\hline RDA & $3 / 87 / 90$ & 2.47 & $0.068^{*}$ & 1.91 & 0.134 & 2.96 & $0.037 * *$ \\
\hline LNA & $3 / 87 / 90$ & 0.81 & 0.491 & 0.44 & 0.722 & 0.16 & 0.923 \\
\hline FNAG & $3 / 87 / 90$ & 2.51 & 0.064* & 2.36 & $.077^{*}$ & 3.40 & $0.021 * *$ \\
\hline MGAG & $3 / 84 / 87$ & 8.05 & $0.000 * * *$ & 6.51 & $0.001 * * *$ & 8.91 & $0.000 * * *$ \\
\hline GPA & $42 / 40 / 82$ & 1.97 & $0.017^{* *}$ & 1.76 & $0.037 * *$ & 1.079 & $0.033 * *$ \\
\hline
\end{tabular}

\section{Motivation Factors Associated with Student Performance}

Grade Make (GMK)

One-Way Analysis of Variance (ANOVA) in Table 3 shows statistically significant relationships between GMK and all three performance measures with strong p-values of $0.000^{* * *}$. Pearson Correlation Coefficients (CORR) in Table 4 also show the relationships are positive and significant, again with p- 
values of $0.000^{* * *}$ across the board. We then test for correlations between GMK and performance measures after controlling for prior ability variables (FNAG, MGAG, and GPA) because Table 5 (Tables 5 to 11 are essential part of the paper but included in the appendix to maintain continuity) shows statistically significant correlation between GMK and two of the three prior ability variables. Table 6 still shows significant positive correlation between GMK and all three performance measures with p-values of $0.002 * * *$ to $0.010^{* * *}$. Finally, Table 7 shows that even after controlling for prior ability variables and the other three motivation variables (CFN, CPA, and GSC), GMK is significantly positively correlated with all three performance measures with p-values ranging from $0.008^{* * *}$ to $0.043^{* *}$. This shows that GMK is not a proxy for prior ability factors and is statistically significant motivation factor distinct from the other three motivation factors. For the Ordinary-Least-Square Regression (OLS) in Tables 8 to 10, GMK coefficient is positive and significant, with p-values ranging from $0.011^{* *}$ to $0.082^{*}$, for all three performance measures for only Models 3 and 4 that exclude the other three motivation variables. Overall, the results support Grade Make (GMK) as the most significant motivation variable explaining students' performance in the UFM course. The results are similar to Gupta and Maksy (2014) who also found Grade Make to be a significant motivation variable in explaining students' performance in an Investments course. In contrast Maksy and Rezvanian (2017) found positive relationship between Grade Make and students' performance in the course for only bivariate tests without controlling for prior abilities.

TABLE 4

PEARSON CORRELATION COEFFICIENTS BETWEEN PERFORMANCE MEASURES AND INDEPENDENT VARIABLES

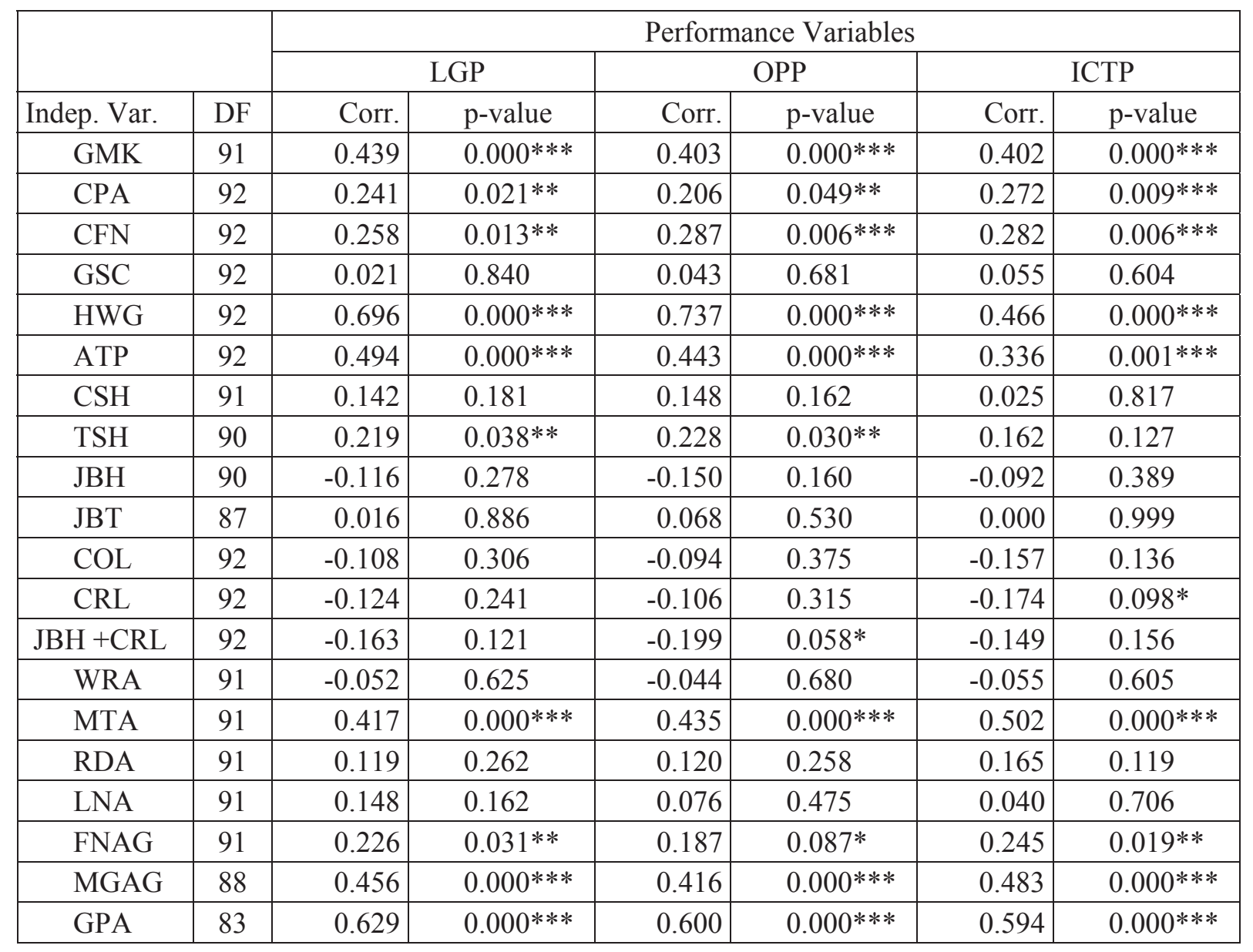


Intention to Take CFA or CFP Exams (CFN)

Table 2 shows that only $17 \%$ of students indicated yes/maybe about taking CFA or CFP exams (CFN). They have 0.78 higher mean LG, 8.73 higher mean OPP, and 8.53 higher mean ICTP. The pvalues are $0.011^{* *}, 0.007 * * *$, and $0.005^{* * *}$ respectively. These results are supported by ANOVA in Table 3 and CORR in Table 4 where the p-value varies from $0.006^{* * *}$ to $0.040^{* *}$. For consistency, we also test for correlation between CFN and performance measures after controlling for prior ability variables even though Table 5 does not show any statistically significant correlation between CFN and prior ability variables. Table 6 again shows significant positive correlation between CFN and all three performance measures with p-values of $0.006^{* * *}$ to $0.015^{* *}$. Finally, Table 7 shows that even after controlling for prior ability variables and the other three motivation variables, CFN is significantly positively correlated with all three performance measures with the p-values ranging from $0.019^{* *}$ to $0.046^{* *}$. This shows that CFN is not a proxy for prior ability factors and is significant motivation factor distinct from the other three motivation factors. For OLS, CFN coefficient has significant p-value of 0.091* in Model 2 for OPP only (Table 9). This does not negate our strong results in Tables 2, 3, 4, 6, and 7. We believe that the way the variable is defined makes it unsuitable for the OLS analysis. Overall the results support CFN as one of the significant motivation variables in explaining students' performance in the UFM course. This is in contrast to Gupta and Maksy (2014) who did not find CFA/CFP to be a significant motivation variable in explaining students' performance in an Investments course. However, Maksy and Rezvanian (2017) found positive significant relationship between course grade and CFA/CFP after controlling for prior abilities and also for multivariate tests.

\section{Intention to Take CPA Exam (CPA)}

With regard to CPA as a motivation factor, Table 2 shows that $34 \%$ of students indicated yes/maybe about taking CPA exam. Their mean LG is 0.58 higher, their mean OPP is 5.18 higher, and their mean ICTP is 6.30 higher. The p-values are $0.020^{* *}, 0.046^{* *}$, and $0.011^{* *}$ respectively. These results are generally supported by ANOVA in Table 3 and CORR in Table 4 where the p-values vary from $0.009^{* * *}$ to 0.130 , with only one out of six statistically insignificant. We also test for correlation between CPA and performance measures after controlling for prior ability variables because Table 5 shows statistically significant correlations between FNAG and MGAG and CPA. Table 6 shows that after controlling for prior ability variables, correlation values are lower with lower level of statistical significance. Finally, Table 7 shows that after controlling for prior ability variables and other three motivation variables CPA is not significantly correlated with any of the three performance measures. This shows that CPA could be a proxy for prior ability variables and is not significant motivation factor distinct from other three motivation factors. This is supported by Table 11 which shows significant positive correlation between CPA and CFN and also GMK. For the OLS tests, CPA coefficient is not significant for any of the three performance measures. Our results are consistent with Maksy and Rezvanian (2017).

\section{Intention to Attend Graduate School (GSC)}

For Grad School, Table 2 shows that $78 \%$ of the students indicated yes or maybe. For the students indicating yes or maybe, their mean LG is 0.46 higher with p-value of 0.108 , their mean OPP is 5.56 higher with p-value of $0.063^{*}$ and their mean ICTP is 5.44 higher with p-value of $0.055^{*}$. All other tests for association between Grad School and performance measures are insignificant and consistent with Gupta and Maksy (2014) and Maksy and Rezvanian (2017).

Overall, the results show that motivation, as measured by GMK and CFN, plays a role in students' performance in the UFM course. Our results are consistent with Paulsen and Gentry (1995) and Nofsinger and Petry (1999), although each of them used different ways to measure the motivation. Nofsinger and Petry (1999) used GPA as one of the motivation variables, our study shows that GMK and CFN are significant motivation variable even after controlling for the GPA. Our results are also consistent with Maksy and Rezvanian (2017) for the CFA/CFP, CPA, and Graduate School variables. 


\section{Effort Factors Associated with Student Performance \\ Homework Grade (HWG)}

ANOVA in Table 3 shows statistically significant relationship between HWG and two of the three performance measures. Table 4 shows significant positive correlations between HWG and all three performance measures, with strong p-values of $0.000^{* * *}$. In Table 6 we test for correlation between HWG and performance measures after controlling for the three prior ability variables because Table 5 shows statistically significant correlation between the HWG and GPA. Table 6 still shows significant positive correlations between HWG and all three performance measures, with strong with p-values of $0.000^{* * *}$ to $0.005^{* * *}$. Finally, Table 7 shows that even after controlling for prior ability variables and the other three effort variables (ATP, CSH, and TSH) HWG is significantly positively correlated with all three performance measures with p-values ranging from $0.000^{* * *}$ to $0.009 * * *$. This shows that HWG is not a proxy for the prior ability factors and is significant effort factor distinct from the other three effort factors. For OLS in Tables 8 to 10, HWG coefficient is significant for all three performance measures in Models 1 to 3 where it is used as an independent variable. The p-values range from $0.000^{* * *}$ to $0.035^{* *}$. Differences in coefficients of HWG between Tables 9 and 10 are $0.160,0.156$, and 0.150 for the three models. This is close to $15 \%$ weight assigned to HWG in OPP (Table 9). Overall, the results support HWG as the most significant of the four effort variables in explaining students' performance in UFM course. The results are consistent with Rich (2006) and Gupta and Maksy (2014) who also found Homework to be a significant effort variable in explaining students' performance in an UFM course and Investments course respectively.

\section{Attendance (ATP)}

The second effort variable, ATP, shows generally consistent relationship with performance measures. ANOVA in Table 3 shows statistically significant relationship with p-values ranging from $0.000 * * *$ to $0.028^{* *}$. Table 4 shows significant positive correlations between ATP and the three performance measures with $\mathrm{p}$-values ranging from $0.000^{* * *}$ to $0.001 * * *$. We also test for correlation between the ATP and performance measures after controlling for prior ability variables because Table 5 shows statistically significant correlation between the ATP and GPA. Table 6 now shows significant positive correlation between ATP and only two of the three performance measures with significance levels of $0.000 * * *$ to $0.004 * * *$. Finally, Table 7 shows that after controlling for prior ability variables and the other three effort variables, ATP is significantly positively correlated only with LG with p-value of $0.039^{* *}$. This shows that ATP may be a proxy for one or more effort variables. Indeed, Table 10 shows strong significant positive correlation between ATP and HWG meaning students who attend class do well in homework too. For OLS in Tables 8 to 10, ATP coefficient is statistically significant for only LG in Models 1 and 2 with p-values of $0.092^{*}$ and $0.016^{* *}$ respectively. Overall, evidence of direct relationship between ATP and performance is weak. However, these results do not indicate that attendance does not matter. ATP is highly correlated with HWG which in turn is a significant variable in explaining performance. Perhaps it can be said that students attending classes but not doing the homework may not improve their performance in the course. Our results are consistent with Chan et al. (1997) who found mixed relationship between attendance and course score for the UFM course. In contrast, Rich (2006) reports statistically significant negative relationship between total absences and students' grades in the UFM course.

\section{Course Study Hours (CSH)}

Table 2 shows that only $12 \%$ of the students indicate studying the recommended six hours or more per week for the course. Their performance is 0.23 higher in mean LG, 3.09 higher in mean OPP, and 1.38 lower in ICTP. However, none of them are statistically significant. Similarly, we find that the relationship between $\mathrm{CSH}$ and performance is statistically insignificant for all other tests. Because the survey was given to students at the beginning of the semester, it is possible that the students did not study for the course as much as they thought they would. 
Total Study Hours (TSH)

For TSH, Table 2 shows that only 13\% of the students indicate studying 20 hours or more per week for all the courses they were taking. Their mean LG is 0.69 higher, their mean OPP is 6.82 higher, and their mean ICTP is 3.71 higher than students who study less than 20 hours per week. Only the first two of these are statistically significant with p-values of $0.054^{*}$ and $0.064^{*}$ respectively. ANOVA in Table 3 shows no statistically significant relationship between total study hours and any of the three performance measures. In Table 4, we find statistically significant positive correlation between TSH and LG and also OPP with p-values of $0.038^{* *}$ and $0.030^{* *}$ respectively. We also test for correlation between TSH and the performance measures after controlling for prior ability variables because Table 5 shows statistically significant correlation between TSH and GPA. Table 6 shows that the results are similar to those in Table 4 but with p-values of only $0.091 *$ and $0.077 *$ respectively. Finally, Table 7 shows that after controlling for prior ability variables and the other three effort variables, TSH is significantly positively correlated only with ICTP with p-value of $0.077^{*}$. For OLS in Tables 8 to 10 , the coefficient for TSH is not significant for any of the models or performance measures. Overall the results show weak relationship, at best, between TSH and the three performance measures. This also could be due to students' inaccurate estimation of their total study hours at the beginning of the semester. Nofsinger and Petry (1999) reported similar results. In contrast, Paulsen and Gentry (1995) reported that "Time, Study, and Effort Regulation" were positively related to the student's grade in the UFM course. Didia and Hasnat (1998) reported very week counterintuitive evidence that the coefficient of hours studied was negative and statistically significant at $10 \%$ level for one of the two OLS models but not for the ordered-probit models.

Overall, HWG is strongly related to students' performance in the UFM course, including the ICTP which does not include HWG as part of the calculation. ATP is also related to students' performance, but it may be due to the fact that students with better ATP also have higher HWG.

Earlier we had mentioned that motivated students should be putting in more effort. Table 11 shows positive correlation between motivation variables (GMK, CPA, CFN, and GSC) and effort variables (HWG, ATP, CSH, and TSH) for 14 out of 16 cases but only five of them are statistically significant at $5 \%$ and one at $10 \%$ level or better. Overall, the results for the relationship between motivation and effort variables are generally positive. This is consistent with Wooten (1998) who found significant positive relationship between motivation and effort. Two of the variables Wooten used to measure effort are homework submissions and class attendance.

\section{Distraction Factors Associated with Student Performance Job Hours (JBH)}

Table 2 shows that $50 \%$ of the students indicated that they work 20 hours or more per week. Compared to students who work less than 20 hours per week or do not work, their mean LG is 0.56 lower, their mean OPP is 6.13 lower, and their mean ICTP is 3.71 lower. The first two are statistically significant with p-values of $0.020^{* *}$ and $0.012^{* *}$ respectively. While none of the other tests show statistically significant relationship between JBH and performance in the UFM course, the results, in Table 2, with regard to JBH are somewhat inconsistent with Chan et al. (1997), Wooten (1998), Maksy and Zheng (2008), Gupta and Maksy (2014), and Maksy and Rezvanian (2017), among others, who found that work hours did not affect students' performance in various Accounting and Finance courses.

\section{Job Type (JBT)}

For JBT, Table 2 shows that $37 \%$ of the students were employed in Accounting, Finance or Businessrelated jobs. However, there is no statistically significant difference in their performance compared to those with other jobs. Of the other tests, only ANOVA (Table 3) shows statistically significant relationship between JBT and performance measures. It shows association between JBT and OPP at pvalue of $0.016^{* *}$ and with ICTP with p-value of $0.097^{*}$. Due to the nature of the ANOVA test the direction of relationship cannot be determined. All other statistical tests show no significant relationship between JBT and students' course performance. These results are consistent with Maksy and Rezvanian (2017). 


\section{Course Load (COL)}

According to Table 2, 26\% of the students were taking six or more courses, however none of the tests show statistically significant relationship between COL and the three performance measures. These results are consistent with Gupta and Maksy (2014). However, Maksy and Rezvanian (2017) showed statistically significant positive relationship between course load and letter grade but for bivariate tests only.

\section{Credit Load (CRL)}

Finally, Table 2 shows that $20 \%$ of the students taking 18 or more credit hours in the surveyed semesters. The apparent discrepancy between course load and credit hours is due to availability of one or two credit hours courses in music performance, physical activity, and health. Students taking 18 or more credit hours earned 0.41 lower mean LG, 3.78 lower mean OPP, and 5.43 lower mean ICTP than students taking less than 18 credit hours. Of these, only 5.43 lower mean ICTP is statistically significant with pvalue of $0.066^{*}$. In Table 4 , we also find -0.174 correlation between CRL and ICTP with statistically significant p-value $0.098^{*}$. None of the other tests show statistically significant relationship between CRL and performance. This result is somewhat inconsistent with Chan et al. (1997) who found no statistically significant relationship between credit load and course score. It is also inconsistent with Didia and Hasnat (1998) who found positive relationship between credit load and students' grades. They argue that these counterintuitive results are occurring because brighter students take more credit hours. However, they did not provide any evidence to support their conjecture. Table 5 in our paper shows that, contrary to their conjecture, there are negative relationships between three prior ability variables and CRL. Two of those are statistically significant.

It is possible that students taking on higher credit load adjust their total time commitment by working fewer hours. Indeed Table 11 shows -0.311 correlation between job hours at credit load with p-value of $0.01 * * *$ or better. To account for this, we test for the association between JBH + CRL and the three performance measures and we find only one statistically significant relationship in Table 4 where the correlation is -0.199 with $\mathrm{p}$-value of $0.058^{*}$. Also, Table 7 shows no statistically significant relationship between CRL and the performance measures even after controlling for JBH and two other distraction variables and the prior ability variables. Finally, Table 11 shows that only six of 16 correlations between four effort (HWG, ATP, CSH, TSH) and four distraction variables (JBH, JBT, COL, and CRL) are negative and only one of the six is statistically significant at $\mathrm{p}$-value $<0.10^{*}$. The evidence does not show that effort is negatively affected by distraction factors. This is inconsistent with Wooten (1998).

\section{Self-Perceived Abilities Factors Associated with Student Performance Math Ability (MTA)}

Tables 3 and 4 show strong association between MTA and all three measures of performance in the UFM course, with p-values of $0.000^{* * *}$ to $0.001 * * *$. We also test for correlation between MTA and the performance measures after controlling for three prior ability variables because Table 5 shows statistically significant correlation between MTA and all three prior ability variables. Table 6 still shows significant positive correlation between MTA and all three performance measures with p-values of $0.000 * * *$ to $0.008 * * *$. Finally, Table 7 shows that even after controlling for prior ability variables and other three selfperceived prior ability variables MTA is significantly positively correlated with all three performance measures with p-values ranging from $0.001^{* * *}$ to $0.011^{* *}$. This shows that MTA is not a proxy for prior ability factors and is significant self-perceived ability factor distinct from the other three factors. The OLS tests, in Tables 8 to 10, show that the MTA coefficients for all four models and for all three measures of performance are significant with p-value of $0.000 * * *$ to $0.023 * *$. Overall, the results support MTA as the most significant of not only the four self-perceived ability variables but also of all the independent variables tested. The results are consistent with Didia and Hasnat (1998) OLS estimates, Rich (2006) who finds consistent positive relationship between students' SAT Math scores and exam percent with p-values of $0.000 * * *$, Grover et al. (2010), and Gupta and Maksy (2014). However, results are inconsistent with Chan et al. (1997) who found no significant relationship between students' self-reported quantitative 
skills and course score. Maksy and Rezvanian (2017) reported significant positive relationship between students' self-perceived math ability and course performance only for bivariate tests not controlling for prior ability, for all other statistical tests they do not find statistically significant relationship between MTA and course performance.

\section{Writing Ability (WRA)}

Table 6 shows that after controlling for the three prior ability variables WRA is significantly negatively correlated with all three performance measures with p-value ranging from $0.045^{* *}$ to $0.074^{*}$. Table 7 shows that after controlling for prior abilities and the other three self-perceived abilities, WRA is significantly negatively correlated to ICTP only with p-value of $0.095^{*}$. The OLS Tables 8 to 10 show WRA with statistically significant negative coefficient in Model 1 for all three dependent variables with p-values ranging from $0.037^{* *}$ to $0.097^{*}$. A possible reason for this counter-intuitive result for WRA could be that students with relatively poor Math ability overestimate their Writing ability and vice-versa. Table 11 shows -0.140 correlation between Math and Writing which provides some support for this conjecture even though it is statistically insignificant. Maksy and Rezvanian (2017), on the other hand, reported weak positive relationship between students' self-perceived writing ability and course performance.

\section{Reading Ability (RDA)}

Of the remaining self-perceived ability variables, only RDA shows significant association with LG and ICTP for ANOVA in Table 3, with p-values of $0.068^{*}$ and $0.037^{* *}$ respectively. None of the correlation or regression coefficients are statistically significant for RDA.

\section{Listening Ability (LNA)}

After controlling for prior ability, LNA is significantly positively correlated with LG with p-value of 0.076* (Table 6). Table 7 shows that after controlling for prior ability and three other self-perceived ability variables, LNA is significantly positively correlated to LG with p-value of $0.051^{*}$.

We consider results related to RDA, LNA, and even WRA to be spurious. These results are consistent with Rich (2006) who found no statistically significant relationship between Verbal SAT and exam percent and also Gupta and Maksy (2014) who did not find statistically significant relationships between students self-reported Writing, Reading, and Learning abilities and student performance in an investments course.

\section{CONCLUSIONS AND RECOMMENDATIONS}

One general conclusion of the study is that students' motivation as measured by their intention to make higher grade is a significant predictor of higher grade in the UFM course despite wide disparity between average GMK of 3.38 and actual average LG of 2.16 as per Table 1. Similarly, students' motivation measured by their intention to take the CFA/CFP exams and, to a lesser extent, their intention to take the CPA exam has strong association with their performance. However, their motivation measured by their intention to go to Graduate School shows statistical significance only for the difference in means test. Overall motivation as measured by GMK and CFN plays statistically significant part in students' performance in the UFM course.

With regard to effort, only HWG and ATP show generally consistent relationship with performance in the course. Of the two other effort variables, CSH does not show any association with performance while TSH shows statistically significant relationship with mean LG and mean OPP using differences in means test (Table 2), Pearson correlation coefficient test (Table 4), and partial Pearson correlation coefficient test (Table 6). Note that the survey was given at the beginning of the semester and students may not have been accurately estimating the hours they will be devoting to the course (CSH). They may have been better at estimating their total study hours (TSH) based on their past study habits. We also find generally positive correlation between the four motivation and the four effort variables with 14 out of 16 
of them positive and six being statistically significant (Table 11). From this we can conclude that there is positive association between motivation and effort variables. This positive association is necessary if higher motivation is to lead to better performance.

Of the four distraction variables, JBH shows statistically significant negative relationship with mean LG and mean OPP (Table 2). However, it does not show any association with the performance measures for any other statistical tests. JBT shows statistically significant association with OPP and ICTP based on ANOVA only (Table 3). COL shows no significant association with any of the three performance measures. CRL has statistically significant negative relationship with ICTP (Tables 2 and 4). Overall, we do not find consistent negative relationship between performance and distraction variables.

Among the four self-assessed prior ability variables MTA is consistently and strongly positively related to all three measures of performance under all the statistical tests based on ANOVA (Table 3), CORR (Table 4), partial CORR (Tables 6 and 7) and OLS for all models (Tables 8, 9, 10). For our study, MTA is the strongest and most consistent explanatory variable for all three measures of performance.

In light of the above discussions, we suggest that faculty motivate students to do homework and attend classes and put sufficient time in their studies. They need to emphasize to their students that if they are motivated to earn higher grades in the UFM course they must do homework, attend classes, and put in sufficient study time.

We show that students working 20 hours or more on the average earn 0.56 lower LG in the UFM course and the difference is statistically significant. In light of this we recommend that students be discouraged from working 20 or more hours per week so that they can earn better grades.

Finally, we recommend that advisors emphasize to students the need to develop strong math ability before taking the UFM course.

\section{STUDY LIMITATIONS AND SUGGESTIONS FOR FURTHER RESEARCH}

This study is subject to some limitations. One limitation is that the study school is a public (or statesupported) university thus the conclusions may not be applicable to private schools. A suggestion for further research is to replicate the study at a private school. Another limitation is that the study school is a residential school and it is possible that the results may not be generalizable to commuter schools. Consequently, another suggestion for further research is to replicate the study at a commuter school. The third limitation is that the study sample is somewhat small relative to the number of variables analyzed hence the results may not be as robust as they would have been if the sample was larger. Final suggestion for further research is to replicate the study using a somewhat larger sample by collecting data over a number of years or multiple professors teaching the same course.

\section{ENDNOTES}

1. Here and for rest of the paper and tables:

* indicates statistically significant at $10 \%$ or better level of significance using two tails test

** indicates statistically significant at $5 \%$ or better level of significance using two tails test

$* * *$ indicates statistically significant at $1 \%$ or better level of significance using two tails test 


\section{REFERENCES}

Babcock, P., \& Marks, M. (2011). The Falling Time Cost of College: Evidence from Half a Century of the Time Use Data. The Review of Economics and Statistics, 93(2), 468-478.

Biktimirov, E. N., \& Klassen, K. J. (2008, January/February). Relationship between Use of Online Support Materials and tudent Performance in an Introductory Finance Course. Journal of Education for Business, 153-158.

Chan, K. C., Shum, C., \& Wright, D. J. (1997). Class Attendance and Student Performance in Principles of Finance. Financial Practice and Education, 7(2), 58-65.

Didia, D., \& Hasnat, B. (1998). The Determinants of Performance in the University Introductory Finance Course. Financial Practice and Education, 1(1), 102-107.

Grover, G., Heck, J., \& Heck, N. (2010). Pretest in an Introductory Finance Course: Value Added? Journal of Education for Business, 85, 64-67.

Gupta, K., \& Maksy, M. (2014, July). Factors Associated with Student Performance in an Investments Course: An Empirical Study. Journal of Finance and Accountancy, 16, 86-112.

Henebry, K., \& Diamond, J. (1998). The Impact of Student and Professor Gender on Grade Performance in the Managerial Finance Course. Financial Practice and Education, 8(1), 94-101.

Ingram, R. W., Albright, T. L., \& Baldwin, A. B. (2002). Financial Accounting - a Bridge to Decision Making. Cincinnati, OH: Thomson South-Western.

Johnson, D. L., Joyce, P., \& Sen, S. (2002). An Analysis of Student Effort and Performance in the Finance Principles Course. Journal of Applied Finance, 12(2), 67-72.

Maksy, M., \& Rezvanian, R. (2017). Factors Associated with Student Performance in Introductory Finance: An Empirical Study at a Public University. Journal of International Business Education, 12, 127-154.

Maksy, M., \& Zheng, L. (2008). Factors Associated with Student Performance in Advanced Accounting and Auditing: An Empirical Study in a Public University. Accounting Research Journal, 21, 1632.

Nosfinger, J., \& Petry, G. (1999, Spring). Student Study Behavior and Performance in Principles of Finance. Journal of Financial Education, 25, 33-41.

Pascarella, E., \& Terenzini, P. (1991). How College Affects Students: Findings and Insights from Twenty Years of Research. San Francisco, CA: Jossey-Bass Publisher.

Paulsen, M. B., \& Gentry, J. A. (1995). Motivation, Learning Strategies, and Academic Performance: A Study of the College Finance Classroom. Financial Practice and Education, 5(1), 78-89.

Rich, S. P. (2006). Student Performance: Does Effort Matter? Journal of Applied Finance.

Sen, S., Joyce, P., Farrell, K., \& Toutant, J. (1997). Performance in Principles of Finance Courses by Students with Different Specializations. Financial Practice and Education, 7(2), 66-73.

Van Ness, B. F., Van Ness, R. A., \& Adkins, R. L. (2000). Student Performance in Principles of Finance: Difference Between Traditional and Internet Settings. Financial Practice and Education, 10(2), 160-166.

Wooten, T. (1998, May). Factors Influencing Student Learning in Introductory Accounting Classes: A Comparison of Traditional and Nontraditional Students. Issues in Accounting Education, 13, 357-373. 


\section{APPENDIX}

TABLE 5

PEARSON CORRELATION COEFFICIENTS BETWEEN PRIOR ABILITY VARIABLES AND INDEPENDENT VARIABLES

\begin{tabular}{|c|c|c|c|c|c|c|c|}
\hline & \multicolumn{6}{|c|}{ Prior Ability Variables } \\
\hline & & \multicolumn{2}{|c|}{ FNAG } & \multicolumn{2}{|c|}{ MGAG } & \multicolumn{2}{|c|}{ GPA } \\
\hline $\begin{array}{c}\text { Indep. } \\
\text { Var. }\end{array}$ & $\mathrm{DF}$ & Corr. & p-value & Corr. & p-value & Corr. & $\mathrm{p}$-value \\
\hline GMK & $90 / 88 / 83$ & 0.097 & 0.362 & 0.298 & $0.005 * * *$ & 0.217 & $0.049 * *$ \\
\hline CPA & $91 / 88 / 83$ & 0.284 & $0.006 * * *$ & 0.288 & $0.007 * * *$ & 0.094 & 0.396 \\
\hline $\mathrm{CFN}$ & $91 / 88 / 83$ & -0.008 & 0.940 & 0.164 & 0.128 & 0.021 & 0.847 \\
\hline GSC & $91 / 88 / 83$ & 0.269 & $0.010 * * *$ & 0.095 & 0.377 & 0.158 & 0.154 \\
\hline HWG & $91 / 88 / 83$ & 0.009 & 0.932 & 0.150 & 0.164 & 0.425 & $0.000 * * *$ \\
\hline ATP & $91 / 88 / 83$ & 0.011 & 0.919 & 0.134 & 0.212 & 0.330 & $0.002 * * *$ \\
\hline $\mathrm{CSH}$ & $90 / 87 / 83$ & 0.099 & 0.351 & -0.136 & 0.208 & 0.167 & 0.131 \\
\hline $\mathrm{TSH}$ & $89 / 86 / 83$ & 0.088 & 0.415 & -0.087 & 0.423 & 0.204 & $0.064 *$ \\
\hline $\mathrm{JBH}$ & $89 / 86 / 81$ & 0.117 & 0.275 & -0.094 & 0.392 & -0.049 & 0.666 \\
\hline JBT & $87 / 84 / 78$ & 0.088 & 0.417 & -0.189 & 0.086 & 0.112 & 0.327 \\
\hline COL & $91 / 88 / 83$ & -0.250 & $0.017 * *$ & -0.275 & $0.010 * * *$ & -0.125 & 0.261 \\
\hline CRL & $91 / 88 / 83$ & -0.252 & $0.016^{* *}$ & -0.250 & $0.019 * *$ & -0.148 & 0.182 \\
\hline $\begin{array}{c}\mathrm{JBH} \\
+ \\
\mathrm{CRL} \\
\end{array}$ & $91 / 88 / 83$ & 0.040 & 0.707 & -0.155 & 0.148 & -0.101 & 0.365 \\
\hline WRA & $90 / 88 / 83$ & 0.062 & 0.563 & -0.026 & 0.809 & 0.228 & $0.039 * *$ \\
\hline MTA & $90 / 88 / 83$ & 0.262 & $0.013 * *$ & 0.350 & $0.001 * * *$ & 0.256 & $0.019 * *$ \\
\hline RDA & $90 / 88 / 83$ & 0.189 & $0.075^{*}$ & 0.066 & 0.544 & 0.280 & $0.010 * * *$ \\
\hline LNA & $90 / 88 / 83$ & 0.147 & 0.166 & -0.108 & 0.318 & 0.077 & 0.491 \\
\hline
\end{tabular}


TABLE 6

PEARSON PARTIAL CORRELATION COEFFICIENTS BETWEEN PERFORMANCE MEASURES AND INDEPENDENT VARIABLES (CONTROLLING FOR FNAG, MGAG, AND GPA)

\begin{tabular}{|c|c|c|c|c|c|c|c|}
\hline \multirow[b]{3}{*}{$\begin{array}{l}\text { Indep. } \\
\text { Var. }\end{array}$} & \multirow[b]{3}{*}{ DF } & \multicolumn{6}{|c|}{ Performance Variables } \\
\hline & & \multicolumn{2}{|c|}{ LGP } & \multicolumn{2}{|c|}{ OPP } & \multicolumn{2}{|c|}{ ICTP } \\
\hline & & Corr. & p-value & Corr. & p-value & Corr. & p-value \\
\hline GMK & 75 & 0.354 & $0.002 * * *$ & 0.308 & $0.006 * * *$ & 0.293 & $0.010 * * *$ \\
\hline CPA & 75 & 0.194 & $0.091^{*}$ & 0.161 & 0.163 & 0.216 & $0.059^{*}$ \\
\hline CFN & 75 & 0.277 & $0.015 * *$ & 0.310 & $0.006 * * *$ & 0.296 & $0.009 * * *$ \\
\hline GSC & 75 & -0.097 & 0.403 & -0.047 & 0.685 & -0.049 & 0.675 \\
\hline HWG & 75 & 0.640 & $0.000 * * *$ & 0.686 & $0.000 * * *$ & 0.316 & $0.005 * * *$ \\
\hline ATP & 75 & 0.401 & $0.000 * * *$ & 0.324 & $0.004 * * *$ & 0.187 & 0.104 \\
\hline $\mathrm{CSH}$ & 75 & 0.133 & 0.248 & 0.140 & 0.225 & -0.012 & 0.917 \\
\hline TSH & 75 & 0.194 & 0.091* & 0.203 & $0.077 *$ & 0.130 & 0.258 \\
\hline JBH & 75 & -0.076 & 0.511 & -0.116 & 0.313 & -0.044 & 0.704 \\
\hline JBT & 73 & 0.015 & 0.895 & 0.087 & 0.458 & 0.012 & 0.917 \\
\hline $\mathrm{COL}$ & 75 & 0.019 & 0.869 & 0.017 & 0.882 & -0.037 & 0.753 \\
\hline CRL & 75 & 0.005 & 0.966 & 0.009 & 0.939 & -0.055 & 0.635 \\
\hline $\begin{array}{c}\mathrm{JBH}+ \\
\mathrm{CRL}\end{array}$ & 75 & -0.088 & 0.447 & -0.136 & 0.239 & -0.068 & 0.559 \\
\hline WRA & 75 & -0.229 & $0.045^{* *}$ & -0.205 & $0.074 *$ & -0.210 & $0.067^{*}$ \\
\hline MTA & 75 & 0.299 & $0.008 * * *$ & 0.335 & $0.003 * * *$ & 0.406 & $0.000 * * *$ \\
\hline RDA & 75 & -0.052 & 0.655 & -0.035 & 0.765 & 0.027 & 0.815 \\
\hline LNA & 75 & 0.203 & $0.076^{*}$ & 0.104 & 0.370 & 0.061 & 0.599 \\
\hline
\end{tabular}


TABLE 7

PEARSON PARTIAL CORRELATION COEFFICIENTS BETWEEN PERFORMANCE MEASURES AND INDEPENDENT VARIABLES (CONTROLLING FOR FNAG, MGAG, GPA, AND OTHER VARIABLES IN THE SAME GROUP)

\begin{tabular}{|c|c|c|c|c|c|c|c|}
\hline \multirow[b]{3}{*}{$\begin{array}{l}\text { Indep. } \\
\text { Var. }\end{array}$} & \multirow[b]{3}{*}{ DF } & \multicolumn{6}{|c|}{ Performance Variables } \\
\hline & & \multicolumn{2}{|c|}{ LGP } & \multicolumn{2}{|c|}{ OPP } & \multicolumn{2}{|c|}{ ICTP } \\
\hline & & Corr. & p-value & Corr. & p-value & Corr. & p-value \\
\hline \multicolumn{8}{|c|}{ Motivation Variables } \\
\hline GMK & 72 & 0.308 & $0.008 * * *$ & 0.265 & $0.023 * *$ & 0.236 & $0.043 * *$ \\
\hline CPA & 71 & 0.068 & 0.568 & 0.059 & 0.625 & 0.085 & 0.474 \\
\hline $\mathrm{CFN}$ & 72 & 0.232 & $0.046 * *$ & 0.273 & $0.019 * *$ & 0.247 & $0.034 * *$ \\
\hline GSC & 72 & -0.099 & 0.399 & -0.050 & 0.675 & -0.049 & 0.676 \\
\hline \multicolumn{8}{|c|}{ Effort Variables } \\
\hline HWG & 72 & 0.590 & $0.000 * * *$ & 0.654 & $0.000 * * *$ & 0.302 & $0.009 * * *$ \\
\hline ATP & 72 & 0.241 & $0.039 * *$ & 0.115 & 0.330 & 0.076 & 0.519 \\
\hline $\mathrm{CSH}$ & 72 & -0.173 & 0.141 & -0.193 & $0.099 *$ & -0.234 & 0.045 \\
\hline TSH & 72 & 0.148 & 0.210 & 0.174 & 0.138 & 0.207 & $0.077^{*}$ \\
\hline \multicolumn{8}{|c|}{ Distraction Variables } \\
\hline $\mathrm{JBH}$ & 70 & -0.086 & 0.474 & -0.124 & 0.298 & -0.071 & 0.551 \\
\hline JBT & 70 & 0.017 & 0.889 & 0.088 & 0.462 & 0.008 & 0.944 \\
\hline $\mathrm{COL}$ & 70 & 0.052 & 0.663 & 0.050 & 0.679 & 0.048 & 0.690 \\
\hline CRL & 70 & -0.055 & 0.645 & -0.054 & 0.652 & -0.072 & 0.545 \\
\hline \multicolumn{8}{|c|}{ Self-Perceived Ability Variables } \\
\hline WRA & 72 & -0.146 & 0.214 & -0.145 & 0.216 & -0.196 & $0.095^{*}$ \\
\hline MTA & 72 & 0.294 & $0.011 * *$ & 0.323 & $0.005 * * *$ & 0.387 & $0.001 * * *$ \\
\hline RDA & 72 & -0.060 & 0.612 & -0.003 & 0.981 & 0.102 & 0.386 \\
\hline LNA & 72 & 0.227 & $0.051^{*}$ & 0.110 & 0.352 & 0.028 & 0.815 \\
\hline
\end{tabular}


TABLE 8

REGRESSION ANALYSIS FOR LETTER GRADE (LG) AS DEPENDENT VARIABLE

\begin{tabular}{|l|l|l|l|l|l|l|l|l|}
\hline & \multicolumn{2}{|c|}{ Model 1 } & \multicolumn{2}{c|}{ Model 2 } & \multicolumn{3}{c|}{ Model 3 } & \multicolumn{2}{c|}{ Model 4} \\
\hline $\begin{array}{l}\text { Indep. } \\
\text { Var. }\end{array}$ & Coeff. & p-value & Coeff. & p-value & Coeff. & p-value & Coeff. & p-value \\
\hline Constant & -2.743 & $0.006^{* * *}$ & -2.841 & $0.001 * * *$ & -2.828 & $0.000^{* * *}$ & -3.137 & $0.001^{* * *}$ \\
\hline GMK & 0.206 & 0.163 & 0.157 & 0.216 & 0.301 & $0.013^{* *}$ & 0.435 & $0.011^{* *}$ \\
\hline CPA & 0.082 & 0.494 & & & & & & \\
\hline CFN & 0.155 & 0.368 & 0.185 & 0.254 & & & & \\
\hline GSC & -0.059 & 0.416 & & & & & & \\
\hline HWG & 0.022 & $0.000^{* * *}$ & 0.021 & $0.000^{* * *}$ & 0.023 & $0.000^{* * *}$ & & \\
\hline ATP & 0.010 & $0.092^{*}$ & 0.012 & $0.016^{* *}$ & & & & \\
\hline TSH & 0.003 & 0.801 & & & & & 0.011 & 0.424 \\
\hline JBH & -0.002 & 0.741 & -0.000 & 0.995 & & & & \\
\hline JBT & -0.014 & 0.931 & & & & & & \\
\hline CRL & -0.034 & 0.264 & -0.024 & 0.411 & -0.042 & 0.125 & -0.029 & 0.444 \\
\hline WRA & -0.300 & $0.037 * *$ & - & $0.064 *$ & & & & \\
\hline MTA & 0.233 & $0.023 * *$ & 0.269 & $0.003 * * *$ & 0.323 & $0.000^{* * *}$ & 0.290 & $0.014 * *$ \\
\hline RDA & 0.185 & 0.198 & & & & & & \\
\hline LNA & 0.093 & 0.468 & & & & & & \\
\hline FNAG. & -0.093 & 0.409 & & & & & & \\
\hline MGAG & 0.162 & 0.217 & 0.168 & $0.094^{*}$ & & & & \\
\hline GPA & 0.552 & $0.003 * * *$ & 0.578 & $0.001 * * *$ & 0.664 & $0.000^{* * *}$ & 1.135 & $0.000^{* * *}$ \\
\hline $\begin{array}{l}\text { Adj. R } \\
\text { DF }\end{array}$ & 0.748 & $17 / 56 / 73$ & 0.758 & $10 / 67 / 77$ & 0.735 & $5 / 77 / 82$ & 0.498 & $5 / 77 / 82$ \\
\hline F & 13.732 & $0.000^{*}$ & 25.134 & $0.000^{* * *}$ & 46.569 & $0.000^{* * *}$ & 17.280 & $0.000^{* * *}$ \\
\hline
\end{tabular}


TABLE 9

REGRESSION ANALYSIS FOR OVERALL POINTS IN PERCENT (OPP) AS DEPENDENT VARIABLE

\begin{tabular}{|l|l|l|l|l|l|l|l|l|}
\hline \multicolumn{3}{|c|}{ Model 1 } & \multicolumn{2}{c|}{ Model 2 } & \multicolumn{3}{c|}{ Model 3 } & \multicolumn{2}{c|}{ Model 4 } \\
\hline Indep. Var. & Coeff. & p-value & Coeff. & p-value & Coeff. & p-value & Coeff. & p-value \\
\hline Constant & 30.752 & $0.003^{* * *}$ & 29.557 & $0.001^{* * *}$ & 24.514 & $0.000^{* * *}$ & 20.949 & $0.037 * *$ \\
\hline GMK & 1.745 & 0.253 & 1.509 & 0.241 & 2.310 & $0.051^{*}$ & 3.859 & $0.033^{* *}$ \\
\hline CPA & 0.501 & 0.686 & & & & & & \\
\hline CFN & 2.479 & 0.167 & 2.805 & $0.091^{*}$ & & & & \\
\hline GSC & -0.234 & 0.756 & & & & & & \\
\hline HWG & 0.258 & $0.000^{* * *}$ & 0.248 & $0.000^{* * *}$ & 0.273 & $0.000^{* * *}$ & & \\
\hline ATP & 0.051 & 0.378 & 0.057 & 0.259 & & & & \\
\hline TSH & 0.009 & 0.939 & & & & & 0.130 & 0.370 \\
\hline JBH & -0.053 & 0.418 & -0.046 & 0.408 & & & & \\
\hline JBT & 0.903 & 0.593 & & & & & & \\
\hline CRL & -0.405 & 0.202 & -0.308 & 0.295 & -0.349 & 0.193 & -0.195 & 0.629 \\
\hline WRA & -2.786 & $0.061 *$ & -1.717 & 0.136 & & & & \\
\hline MTA & 3.381 & $0.002 * * *$ & 3.582 & $0.000^{* * *}$ & 4.150 & $0.000^{* * *}$ & 3.768 & $0.003 * * *$ \\
\hline RDA & 2.297 & 0.126 & & & & & & \\
\hline LNA & -0.131 & 0.922 & & & & & & \\
\hline FNAG. & -1.251 & 0.287 & & & & & & \\
\hline MGAG & 1.171 & 0.388 & 0.855 & 0.397 & & & & \\
\hline GPA & 4.773 & $0.013 * *$ & 5.332 & $0.003 * * *$ & 5.586 & $0.000^{* * *}$ & 11.074 & $0.000^{* * *}$ \\
\hline $\begin{array}{l}\text { Adj. R } \\
\text { DF }\end{array}$ & 0.752 & $17 / 56 / 73$ & 0.769 & $10 / 67 / 77$ & 0.767 & $5 / 77 / 82$ & 0.472 & $5 / 77 / 82$ \\
\hline F & 13.986 & $0.000^{* * *}$ & 26.592 & $0.000^{* * *}$ & 55.013 & $0.000^{* * *}$ & 15.649 & $0.000^{* * *}$ \\
\hline
\end{tabular}


TABLE 10

REGRESSION ANALYSIS FOR IN-CLASS TESTS IN PERCENT (ICTP) AS DEPENDENT VARIABLE

\begin{tabular}{|l|l|l|l|l|l|l|l|l|}
\hline & \multicolumn{2}{|c|}{ Model 1 } & \multicolumn{2}{c|}{ Model 2 } & \multicolumn{3}{c|}{ Model 3 } & \multicolumn{2}{c|}{ Model 4} \\
\hline $\begin{array}{l}\text { Indep. } \\
\text { Var. }\end{array}$ & Coeff. & p-value & Coeff. & p-value & Coeff. & p-value & Coeff. & p-value \\
\hline Constant & 38.086 & $0.004^{* * *}$ & 36.583 & $0.001^{* * *}$ & 29.805 & $0.001^{* * *}$ & 28.242 & $0.002^{* * *}$ \\
\hline GMK & 2.073 & 0.287 & 1.741 & 0.284 & 2.592 & $0.082^{*}$ & 3.276 & $0.045^{* *}$ \\
\hline CPA & 1.033 & 0.514 & & & & & & \\
\hline CFN & 2.947 & 0.198 & 3.356 & 0.110 & & & & \\
\hline GSC & 0.074 & 0.938 & & & & & & \\
\hline HWG & 0.098 & $0.035^{* *}$ & 0.092 & $0.022^{* *}$ & 0.123 & $0.001^{* * *}$ & & \\
\hline ATP & 0.036 & 0.623 & 0.047 & 0.459 & & & & \\
\hline TSH & 0.018 & 0.903 & & & & & 0.062 & 0.634 \\
\hline JBH & -0.079 & 0.339 & -0.064 & 0.361 & & & & \\
\hline JBT & 1.073 & 0.618 & & & & & & \\
\hline CRL & -0.606 & 0.136 & -0.502 & 0.177 & -0.545 & 0.108 & -0.477 & 0.192 \\
\hline WRA & -3.138 & $0.097 *$ & -1.980 & 0.173 & & & & \\
\hline MTA & 3.865 & $0.005^{* * *}$ & 4.060 & $0.001^{* * *}$ & 4.857 & $0.000^{* * *}$ & 4.687 & $0.000^{* * *}$ \\
\hline RDA & 2.036 & 0.286 & & & & & & \\
\hline LNA & 0.308 & 0.856 & & & & & & \\
\hline FNAG. & -1.590 & 0.289 & & & & & & \\
\hline MGAG & 1.441 & 0.405 & 1.173 & 0.358 & & & & \\
\hline GPA & 6.792 & $0.006 * * *$ & 7.285 & $0.001 * * *$ & 7.382 & $0.000^{* * * *}$ & 9.834 & $0.000^{* * *}$ \\
\hline $\begin{array}{l}\text { Adj. R } / \\
\text { DF }\end{array}$ & 0.533 & $17 / 56 / 73$ & 0.576 & $10 / 67 / 77$ & 0.581 & $5 / 77 / 82$ & 0.514 & $5 / 77 / 82$ \\
\hline F & 5.899 & $0.000^{*}$ & 11.479 & $0.000^{* * *}$ & 23.787 & $0.000^{* * * *}$ & 18.373 & $0.000^{* * *}$ \\
\hline
\end{tabular}




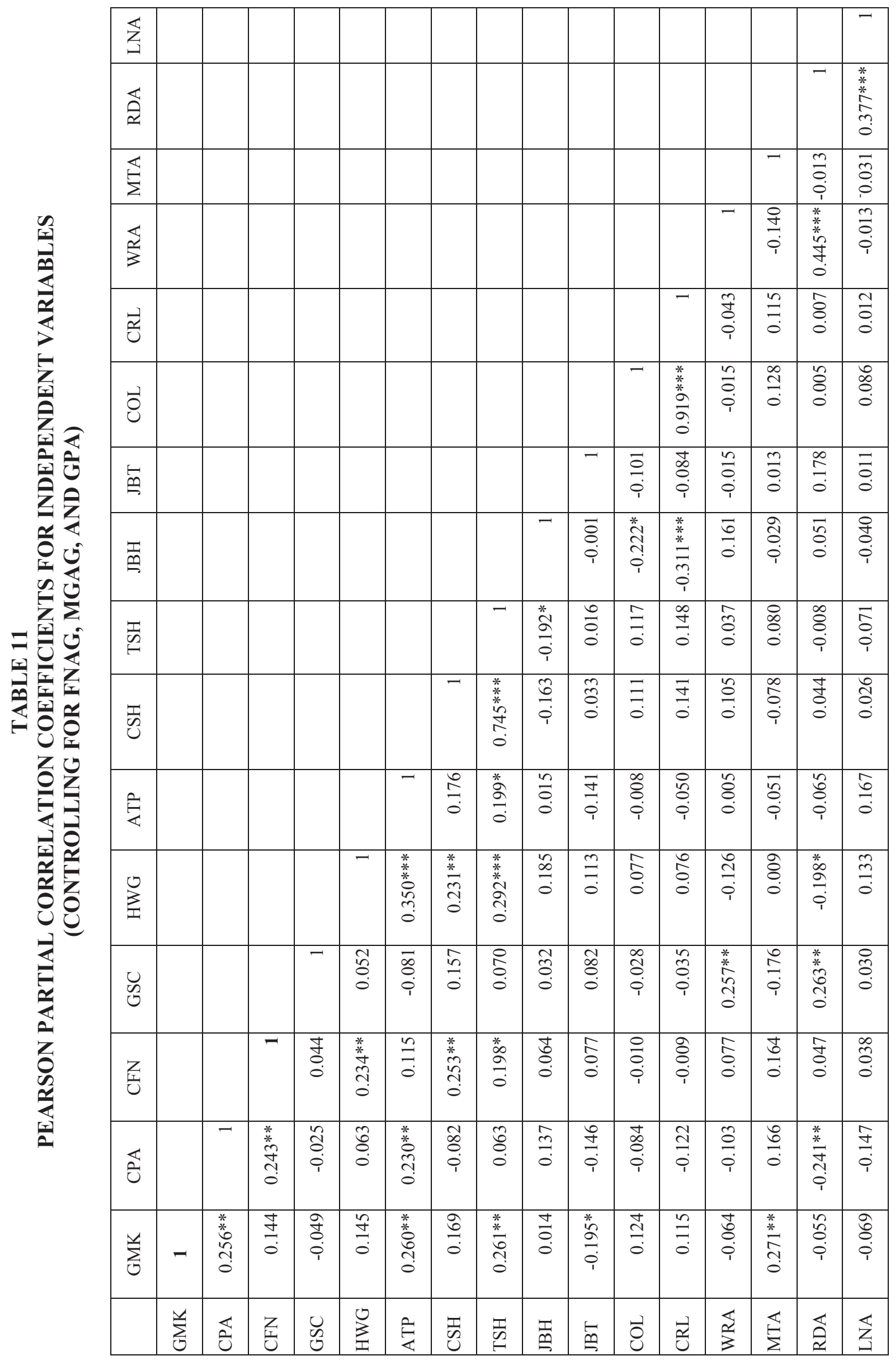

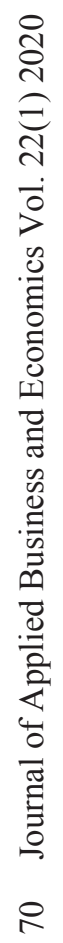

